\title{
SUSTAINABLE GROWTH MANAGEMENT AT NAPLES INTERNATIONAL AIRPORT, ITALY
}

\author{
MICHELE MIEDICO \\ Naples International Airport, Italy
}

\begin{abstract}
Naples International Airport is a perfect example of a "City Airport" as it is only $5 \mathrm{~km}$ away from the city centre. Managed by Gesac, in 2017 passenger traffic amounted to 8.6 million, with a rate of growth 3 times the European and Italian average. With the objective of sustainable growth, Gesac is currently adopting an integrated action plan, backed by a significant investment programme. Specific devices are used in the terminal to manage water consumption, which resulted in a $25 \%$ savings of potable water in the last year, despite the growth in passenger traffic. Like a small city, the airport produces 1,200 tonnes of waste. Sorted waste collection, which was $62 \%$ in 2017 , has set a target of $65 \%$ for 2018 to be achieved by door-to-door waste collection. In order to reduce energy consumption, Gesac adopted a smart management system of lights and air conditioning in the passenger terminal and has begun the construction of a new power generation plant designed to produce enough energy to meet the aerodrome's electric, thermal and refrigerating needs. These activities are included in the Airport Carbon Accreditation program, developed by the Airport Council International (ACI) to reduce emissions worldwide. Gesac is scheduled to obtain certification for the highest level (3+"Neutrality") by 2018. Aircraft noise is a main issue in the sustainable growth domain. In 2005, Naples International Airport was the first airport in Italy to install a noise monitoring system and to control the noise abatement procedures and, consequently, to reduce its initial footprint by more than $26 \%$, and the population exposed by $52 \%$. Gesac carefully monitors third party risk and adopts smart mitigation actions. These include delocalization of general aviation traffic with the creation of the Campania Airport Network.

Keywords: city airport, sustainable growth, noise contours, emission reduction, waste management, third party risk, water pollution, Airport Carbon Accreditation, energy consumption, land use.
\end{abstract}

\section{INTRODUCTION}

Naples International Airport was the first Italian airport to be privatized when BAA acquired $65 \%$ of the shares in 1997. In 2010, F2i, the largest investment fund in Italy, dedicated to infrastructures, acquired the majority of the shares. Currently, Adrian, the French investment fund, and the Credite Agricole Bank also have holdings in the company.

The airport's catchment area, the most densely populated in Italy (7 million people), is located close to southern Italy's main tourist attractions which include 6 UNESCO World Heritage sites.

Naples International Airport is a perfect example of a "City Airport" as it is located only 15 minutes away from Naples city centre (less than $5 \mathrm{~km}$ ). It also has good connections with the city and the entire region (highways) and is close to the port of Naples as well. The metro station is scheduled to directly connect the airport with the city centre in 2019.

The volume of traffic in 2017 was 8.6 million passengers, $65 \%$ of whom were international, which represents a $27 \%$ increase over the previous year, 3 times greater than the average for European airports and 4 times greater than the average for Italian airports.

In 2017, Naples International Airport was the 2nd European Airport in the "5-10 million passenger category" and the 8th in the world in terms of attaining the greatest increase in passenger traffic and providing service to 99 destinations.

This extremely rapid growth in traffic has led to some critical issues in relation to environment management and to the need to elaborate a strategy for sustainable development. 


\section{NAPLES INTERNATIONAL AIRPORT: \\ BEST PRACTICES FOR SUSTAINABLE GROWTH}

Due to the airport's characteristics as regards its location in the middle of the city, in the past, any growth in traffic has always been balanced by many specific measures implemented to better understand, monitor and mitigate its environmental impact. Some of these measures include defining noise abatement procedures and noise contours in cooperation with national and local Authorities, the ATC provider and the airlines, implementation of a noise monitoring system, two engine testing stands and equipment on the apron stands for $400 \mathrm{~Hz}$ and air conditioning supply.

Owing to the boom in low cost traffic during the course of the last two years, the airport has begun to re-think its strategic plan for sustainable growth, and has envisaged an integrated action plan, in which all the dots are connected to create a more complete picture.

\section{THE FOUR ELEMENTS}

In ancient times, it was believed that nature was regulated by single elements in connection with each other. This was the Four Elements Theory developed by Empedocle in the 5th century BC.

"Now hear the fourfold roots of everything: Zeus the shining fire, enlivening Hera, Hades and Nestis, moistening mortal springs with tears" [1].

Fire, Earth, Water and Air are the ancient roots of the structure of the world, that have become the four areas of action for attaining sustainable growth at the airport.

Ideally, inspiration was drawn from the "Airport Archaeological Path" exhibit inaugurated last year, as well an exhibit of four old art masterpieces in our airport which was chosen to symbolize the protection of the four elements.

The statue of the Nike may be considered as representative of the Water element, as the statue was a figurehead of a ship, and she ideally protects this element from being wasted and polluted.

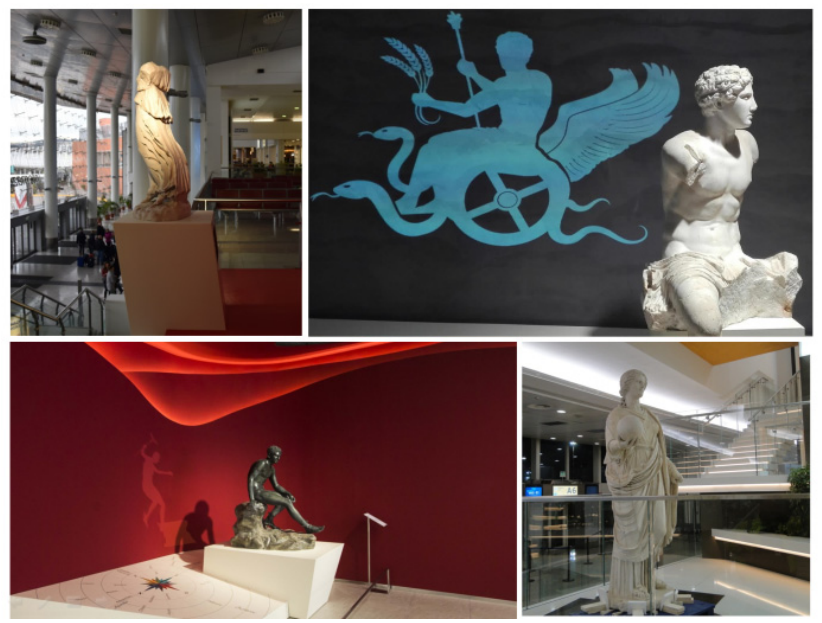

Figure 1: The four statues of the Archaeological Airport Exhibition. From top left: Nike (certified copy of the original); Triptolemus (original 1st century BC statue); Hermes (certified copy of the original); and Urania (original 1st century BC statue). 
Earth is represented by Triptolemus, the ancient Greek God who taught agriculture, a symbol of the reduction in soil consumption, waste management and the monitoring of obstacles.

Ideally Hermes, the God who gave Fire to man, presides energy management and the reduction of emissions.

Finally, Urania, the ancient Goddess of Astronomy, ideally protects the element of Air from noise pollution and third party risk.

\subsection{The Water element: water consumption and pollution}

The complete availability of potable water is one of the most important achievements of modern times yet, concurrently, one of the most underestimated. It's incredible how almost everywhere in "civilized" countries you can simply turn on the tap in your kitchen and drink fresh, potable water. And it is incredible how sometimes people tend to just leave water running and waste it! Awareness of how important it is to save potable water led us to adopt specific devices in the passenger terminal to manage water consumption. And the result was that last year we saved $25 \%$ of potable water despite a $26 \%$ increase in passenger growth.

With a view to the near future, we are now implementing a reclaimed water system to depurate toilet flushing water to be used for specific activities which do not require the use of potable water, such as fire-fighting activities, training activities and the watering of gardens.

\subsection{The Earth element: land use management}

Of all the means of transport, air travel is the means which requires the least amount of land consumption. However, even if building an airport requires very little land as compared to rail or highways, land acquisition is always an issue for airport expansion. This is due to the fact that airports are often surrounded by urbanized areas, generally known as "aerotropolis". In the case of Naples International Airport - or city airports in general - this issue is critical. Land acquisition is not possible without demolishing buildings or infrastructure such as streets, highways and so on.

For this reason, the Naples International Airport Master Plan is based on "smart" management of the available areas. We plan to demolish old buildings to re-build new facilities with a smarter approach; the new infrastructure is based on standard patterns and may be suitable for multiple purposes. For example, an old Avio maintenance hangar was converted into an Areoclub facility and, in the future, it will be part of a planned baggage handling system expansion.

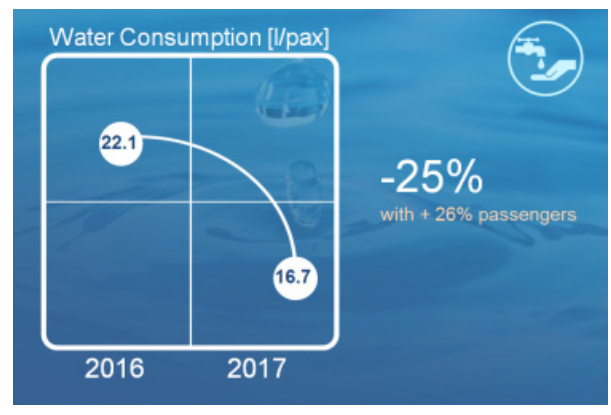

Figure 2: Reduction in water consumption. 


\subsection{The Earth element: waste management}

Waste management means avoiding soil pollution. Airports may be considered as small cities with shops, car parks, restaurants and other facilities that produce tonnes of waste. By way of example, a regional airport like Naples International Airport with 8.6 million annual passengers produces 1,200 tonnes of waste, which is almost equal to the annual waste production of Ravello, the wonderful city on the Amalfi Coast (nearly 1,366 tonnes/year).

In 2017, through the implementation of sorted waste collection, $62 \%$ was differentiated and given to the recycling industry, and the remaining 38\% was given to third parties to be used for energy production. We also signed a voluntary agreement to recuperate and recycle paper waste in Naples Airport.

Other measures include the building of modern facilities to accommodate waste management and sorting processes, and specific programmes for waste sorting such as doorto-door waste collection in all the airport buildings.

Naples International Airport is also conducting several information and awareness campaigns to engage all airport stakeholders and passengers in the recycling culture, for instance a campaign has been introduced to reduce the use of plastics.

\subsection{The Earth element: obstacle management}

The formation of the terrain in the surrounding areas is critical for airport operations. Elevated sites like hills or mountains, as well as buildings and antennas are obstacles for air navigation. And the closer they are to the airport, the more dangerous they are for air navigation. This means that any new construction in close proximity of airports should be avoided, as it may interfere with airport operations. This is quite an issue when airports, such as Naples International Airport, are located in the middle of cities, as this may result in blocking the development of large areas of the city.

In Italy, the ATC provider (ENAV) publishes obstacle charts illustrating any obstacles which interfere with airport operations. According to EU Reg. 139/14, which defines the rules for airport construction and management for all European countries, the airport company is to monitor the aerodrome and its surrounding areas, markings and lighting obstacles. Around the Naples aerodrome there are over 1,200 infringements of obstacle protection surfaces, with 640 physical obstacles. Pursuant to EU Reg. 139/14, all obstacles must be illuminated, which would result in lighting a great part of the airport's surroundings, however, obstacle lighting may be omitted if the obstacle is shielded by another obstacle. For this reason Gesac, in cooperation with the Netherland Aerospace Agency NLR, has conducted an aeronautical study-aimed at identifying those "dominant" obstacles which shield other obstacles. The results of the study identified 58 dominant obstacles out of a total of 640 obstacles. All the dominant obstacles have been illuminated and Gesac conducts a yearly monitoring campaign, checking the status of all the lights. In the near future, Gesac plans to install automatic systems on dominant obstacles in order to have a live monitoring system for the obstacle network.

\subsection{The Fire element: energy and emission management}

It is quite obvious that sustainable growth and traffic development are closely connected: more passengers means increased interaction with the environment. For this reason, sustainable growth begins with reducing energy consumption, as well as direct and indirect 
emissions. This translates into strategic actions like adopting smart solutions to minimize the impact of aircraft operations on the environment and the energy consumption.

In the field of energy management, a specific survey conducted in recent years showed that $78 \%$ of the terminal's total consumption was subject to energy efficiency.

For this reason, Gesac began an ambitious programme to update technology in the terminal in order to reduce electric energy consumption. This programme included the use of LED technology for lights and public information monitors, as well as a smart management system of lights and air conditioning in the passenger terminal which controls and adjusts the intensity of light and temperature in the passenger terminal according to natural conditions of light and the external temperature.

This is only the first step of the programme, that includes the construction of a new power generation plant, which is expected to be completed by 2019 .

The new power generation plant has been designed to achieve enhanced levels of energy efficiency by producing the energy to meet the electric, thermal and refrigerating needs of the aerodrome.

The plant will use methane gas to produce enough electricity (over $5000 \mathrm{MWh} /$ year) and hot water to serve the passenger terminal, the cargo terminal and other office buildings in the immediate vicinity. The reduction of $\mathrm{CO}_{2}$ emissions may be estimated to 900 tonnes/year and, in combination with other activities, this will help us to reach level $3+$ in the Airport Carbon Accreditation (ACA) program, developed by the Airport Council International (ACI) to reduce emissions worldwide.

\subsection{The Fire element: emission management}

Airports are the centre points of a complex web of aircraft movements, technical operations and surface access transport. For this reason, their $\mathrm{CO}_{2}$ emissions may be addressed in a variety of ways. These can include energy efficiency, the use of hybrid, electric or gaspowered service vehicles, collective transport improvement, working with airlines and air traffic management to reduce runway taxiing times and implementing green landing processes.

All these activities are included in the ACA program, developed by the ACI in order to reduce airport-generated emissions. This program has four levels of certification which correspond to four different stages of performance in emission reduction [2].
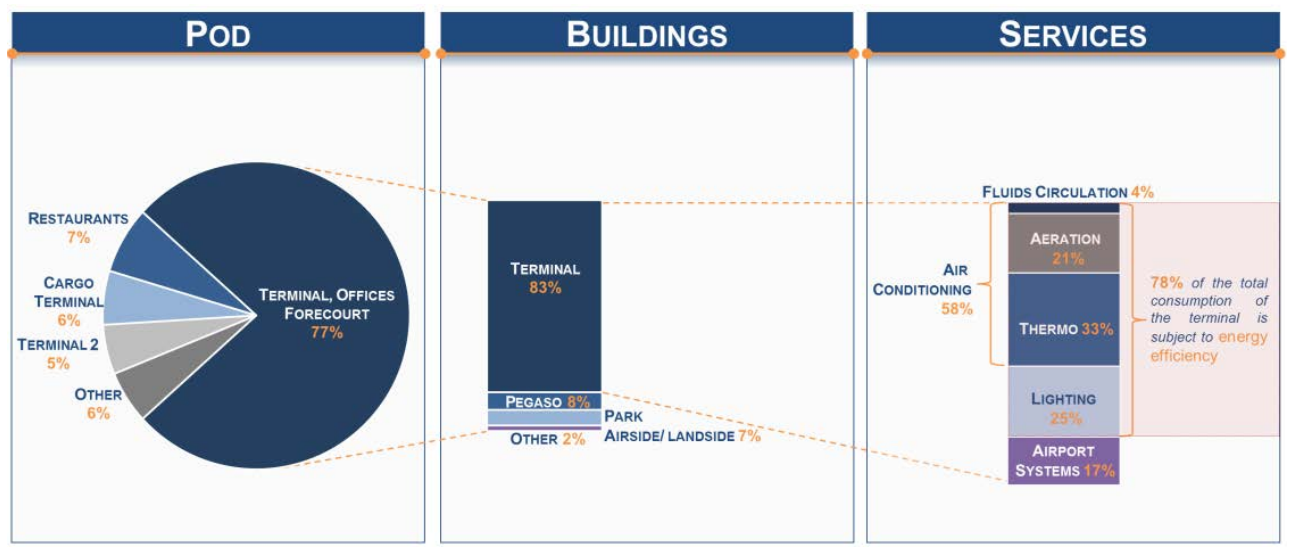

Figure 3: The areas of energy efficiency in the terminal are air conditioning and lighting. 


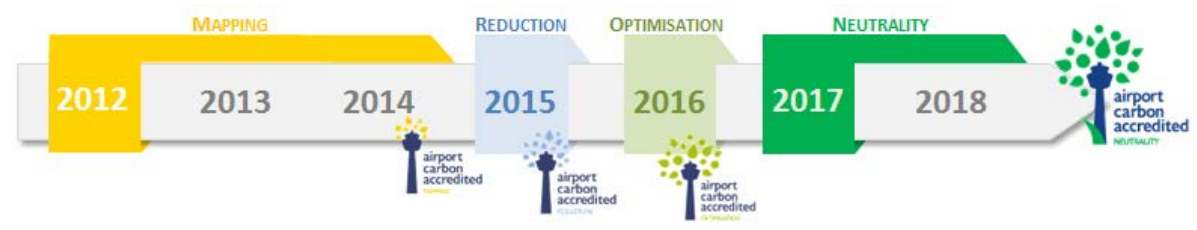

Figure 4: The road-map for the Airport Carbon Accreditation program (ACA).

Each stage of the program is certified by an independent third party in accordance with ISO14064 (Greenhouse Gas Accounting), following the principles of the World Business Council for Sustainable Development (WBCSD) and the World Resources Institute (WRI) "Greenhouse Gas Protocol" Corporate Accounting and Reporting Standard.

When considering the emissions from aircraft within the airport perimeter and on final approach and initial departure, ACA uses the International Civil Aviation Organisation's (ICAO) definition of the landing-take off cycle and requires airports to comply with these definitions.

In general terms, emissions are grouped in three different sources, classified as "Scopes 1,2 and $3 "$.

Scopes 1 and 2 are related to emissions directly under the control of airport management, while Scope 3 emissions are not under the direct control of the airport but may be influenced.

In the last year, Gesac has implemented several direct and indirect activities in order to reduce $\mathrm{CO}_{2}$ emissions, mostly related to Scopes 1 and 2.

A reduction in emissions was obtained by most of the vehicle fleet operating in the airport. This activity was adopted by Gesac as well as by handlers and other stakeholders.

Gesac has also developed many initiatives to monitor and optimize the means of transport to and from the airport by encouraging collective transport such as public buses. With the objective of finding innovative and smart solutions to the problem of airport access, Gesac launched "Airport Access HACK", an open innovation project in collaboration with University of Naples Federico II to explore sustainable mobility solutions for passengers and operators.

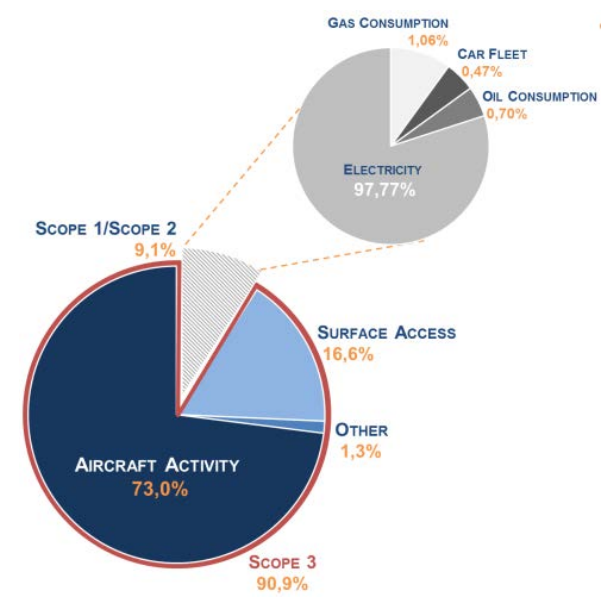

Figure 5: Emissions are classified in three groups: Scopes 1, 2 and 3. 
Direct reduction was obtained with several environmental awareness campaigns in three areas, dedicated to "Energy Consumption Reduction", "Sustainable Mobility" and "Waste Management", respectively.

These activities included several events held in cooperation with the national radio broadcast, Legambiente, and other national and international stakeholders. Level 3+ "Neutrality" is expected to be attained by 2018.

\subsection{The Air element: noise management}

With regards to sustainable growth, aircraft noise is the main issue, as it directly involves thousands of people living in the vicinity of the airport. Moreover, the city's three hills are affected by overflying operations, and this occasionally gives rise to safety concerns by inhabitants who are alarmed by aircraft continuously flying over their properties.

In Italy, noise management is conducted through a specific airport committee which includes the airport operator, the Italian CAA and ATC provider, the airlines as well as representatives of the city and the Ministry of Environment.

The main scope of the commission is to measure, mitigate and manage aircraft noise, as well as to introduce noise abatement procedures, which, in Naples, are designed to minimize overflying of the city and to balance the use of the runway.

In accordance with ICAO Document 8168 , the commission defined a flight average path in order to ensure compliance with noise abatement procedures and established a system of penalties (fines) for airlines in violation of these procedures.

In 2005, Naples International Airport was the first airport in Italy to install a noise monitoring system certified by the Ministry of the Environment. The system is made up of seven control stations in close proximity of the airport and one mobile station.

When compared to the initial 2001 footprint, the controls revealed that, despite an increase in air traffic movements of more than $17 \%$, there was a $26 \%$ reduction in the footprint and a $52 \%$ reduction in the population exposed.

\subsection{The Air element: third party risk management}

Third party risk is the risk associated with the likelihood that people living in the immediate vicinity of an airport may be involved in an air accident. It is necessary to begin with the premise that air transport is one of the safest modes of transport, above all because for more than seventy years, it has been operated with relatively new aircraft, with very detailed maintenance programs and in a fully regulated and mature operating environment.

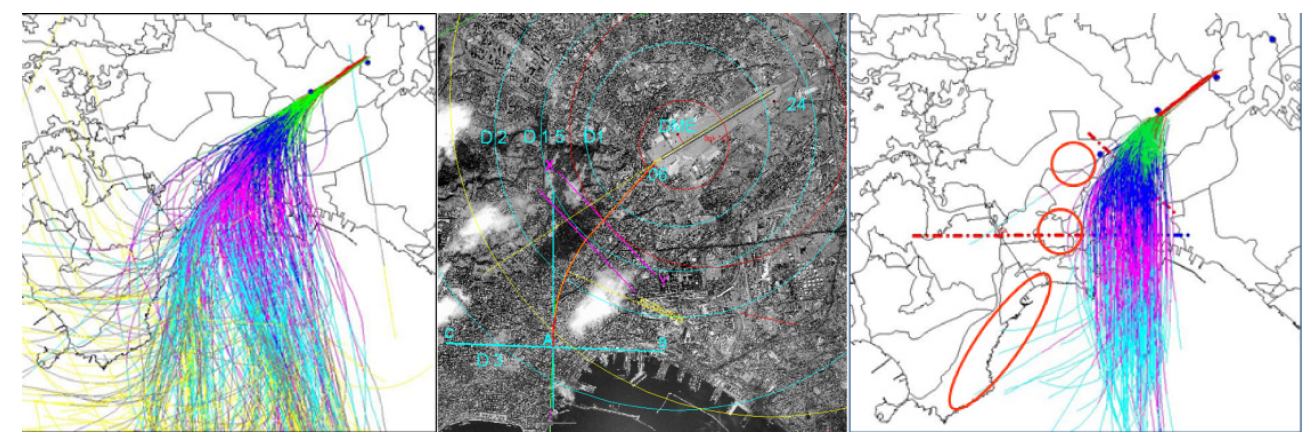

Figure 6: The noise abatement procedure monitoring program. 
In any case, considering that airports generate concentrations of air traffic in limited portions of the territory, in addition to the fact that accidents generally occur in the early stages of take-off or landing, it is legitimate to raise the issue of the possible involvement of the population in the immediate vicinity of the airports.

In the Airport Planning Manual - Part II - Cap 5, the ICAO states that "to prevent the Third Party Risk from becoming an element of emotional assessment in the definition of airport development, objective and accurate assessments are necessary to provide the right support to local authorities". In particular, the ICAO indicates the experience of the Dutch Government with the NLR Aerospace Agency as a correct scientific methodology for calculating third party risk around airports. Moreover, the governments of Great Britain and Italy, through the ENAC, have also developed various scientific methodologies for the calculation of third party risk. All these methodologies are based on the definition of the probability that a person living near the airport may be involved in a plane crash, and in very specific areas, attributes a probability of 1 in 10,000, 1 in 100,000 and 1 in a million die due to this accident. These areas are identified by specific contours called "iso-risk". These curves, according to the traffic operated by an airport, identify portions of the territory in the airport's surroundings within which a person has a probability of 1 in 10,000, 1 in 100,000 and 1 in a million of dying as a result an aircraft accident.

Since 2006, Gesac has carefully monitored "iso-risk" development and has demonstrated that these contours have been retracting steadily over the years. Gesac has also developed several proposals for further mitigation of the risk, with a specific action plan. The main proposal involves delocalization of general aviation traffic, a major component of risk, and which will now be possible to implement thanks to the creation of the Campania Airport Network. Because of this mitigation action, it will be possible to support traffic of over 90,000 movements without a corresponding increase in iso-risk curves, and, consequently, of potentially affected territory.

\section{REFERENCES}

[1] Kingsley, P., Ancient Philosophy, Mystery, and Magic: Empedocles and Pythagorean Tradition, Oxford University Press, 1995.

[2] Airport Carbon Accreditation, Online. www.airportcarbonaccreditation.org/. 